\section{The pros and cons of early diagnosis of dementia}

We read the paper 'The pros and cons of early diagnosis of dementia' published by Fox et al with great interest, which raised the question of how Brazilian doctors' knowledge on the detection of cognitive impairment in older people could be improved. Such papers can help us discuss the paths we should take regarding early detection of dementia. Questions concerning the pros and cons' in an aged, developed nation with a model healthcare system as the UK may serve to help a relatively young nation like Brazil, whose health system is still under construction', to make better decisions in the future. The Brazilian population has aged rapidly in the last three decades (from 43 years in 1950 to 74 in 2011) due to improvements in health care coupled with a lower fertility rate. ${ }^{2}$ Since 1988, all Brazilian citizens have had the right to free health care under the 'Unified Health System' (UHS) ${ }^{2}$ whose core function, at least in theory, is the provision of primary care. UHS health practitioners play a major role in dementia issues since $75 \%$ of our population receive health care exclusively from the UHS.

Previous studies have shown Brazil's dementia prevalence to be similar to rates observed worldwide. ${ }^{3,4} \mathrm{~A}$ focus of interest for researchers has been to verify whether UHS GPs have detected cognitive impairment in their caseload of older patients during routine check-ups. We conducted a study ${ }^{5,6}$ in which a geriatrician randomly screened 248 older people from the primary care sector. Cases suspected of cognitive impairment underwent a complete assessment (neuropsychological, blood exams, and CT). After expert consensus, the 43 patients found to have either mild cognitive impairment or dementia had their medical records checked with a striking finding: only $16 \%$ of these 43 patients' GP medical records registered a cognitive complaint or specific diagnosis.

To ascertain whether GPs in the UHS had good knowledge on dementia issues, another study was conducted involving the application of a 'knowledge quiz' to a convenience sample of 24 GPs. This unpublished data collected from this preliminary study using the Turner et al questionnaire revealed that the GPs held only $50 \%$ of the basic knowledge required for early detection of dementia (mean score $7.08 \pm 2.10$, range $0-14$ ). Thus training the GPs to deal with dementia appears to be the way forward in enhancing care for the older population in Brazil.

Alessandro Ferrari Jacinto,

MD, PhD, Department of Psychiatry,

Universidade Federal de São Paulo, Rua São

Carlos do Pinhal, 508/121 -

São Paulo/SP - 01333-000.

E-mail: alessandrojacintolauol.com.br

Ricardo Nitrini, Sonia Maria Dozzi Brucki, Claudia Sellitto Porto,

Department of Neurology, Universidade de São Paulo.

Fabio Gazelato de Mello Franco,

MD, PhD, Hospital Israelita Albert Einstein.

Vanessa de Albuquerque Citero,

MD, PhD, Department of Psychiatry, Universidade Federal de São Paulo.

\section{REFERENCES}

1. Fox C, Lafortune L, Boustani M, Brayne C. The pros and cons of early diagnosis of dementia. $\mathrm{Br} J \mathrm{Gen}$ Pract 2013; 63(612): 510-512.

2. Brasilia: Unified Health System. Primary care units. http://wnw.brasil.gov.br/sobre/health/service/ primary-care-units (accessed 5 Aug 2013).

3. Herrera E, Caramelli P, Silveira ASB, Nitrini R. Epidemiologic Survey of dementia in a communitydwelling Brazilian population. Alzheimer Dis Assoc Disord 2002; 16(2): 103-108.

4. Nitrini R, Mathias SC, Caramelli P, et al. Evaluation of 100 patients with dementia in São Paulo, Brazil: correlation with socioeconomic status and education. Alzheimer Dis Assoc Disord 1995; 9(3): 146-151.

5. Jacinto AF, Brucki SMD, Porto CS, et al. Detection of cognitive impairment in the elderly by general internists in Brazil. Clinics 2011; 66(8): 1379-1384.

6. Jacinto AF, Brucki SMD, Pereira AS, et al. Screening of cognitive impairment by general internists using two simple tests. Neuropsychologia 2012; 6: 42.

7. Turner S, lliffe S, Downs M, et al. General practitioners' knowledge, confidence and attitudes in the diagnosis and management of dementia. Age Ageing 2004; 33(5): 461-467.

DOI: 10.3399/bjgp13X671551

\section{Long-acting reversible contraception}

I would like to draw the attention of your readers to the conclusions of a paper recently published in the Journal of Family Planning and Reproductive Healthcare, ${ }^{1}$ the conclusion of which is that the levonorgestrel-releasing intrauterine system (LNG IUS; Mirena ${ }^{\circledR}$ Bayerl should be offered first-line without restriction to young and nulliparous women.

It is now 8 years since the National Institute for Health and Care Excellence (NICE) issued its guidance encouraging increased access to long-acting reversible contraception (LARC). ${ }^{2}$ LARC methods are more cost-effective than the combined oral contraceptive pill and will reduce the number of unintended pregnancies. This includes the 'fit and forget' use of the IUS. ${ }^{3}$ The IUD/IUS is not contraindicated in young nulliparous women of any age and this message seems not to be reaching our GP colleagues with nine out 10 GPs still advising women to use the contraceptive pill as a first-line choice for young nulliparous women. ${ }^{4}$

The overriding message is that the levonorgestrel-releasing IUS is a firstline contraceptive option for young and nulliparous women.

\section{Scott Wilkes,}

GP/Hon Clinical Senior Lecturer, Institute of Health and Society, Institute of Health \& Society, Baddiley-Clark Building, Richardson Road, Newcastle upon Tyne, NE2 4AX. E-mail: scott.wilkes@anewcastle.ac.uk

\section{REFERENCES}

1. Armitage CM, Mitchell C, Wigan C, Smith DA. Uptake and continuation rates of the intrauterine system in a university student general practice population in the UK. J Fam Plann Reprod Health Care 2013; 39(3): 186-189.

2. National Institute for Health and Clinical Excellence. Long-acting reversible contraception. CG30. London: NICE, 2005. http://nice.org.uk/nicemedia/ live/10974/29912/29912.pdf (accessed 5 Aug 2013).

3. Draper IB, Haque MS, McManus RJ. Routine intrauterine device checks: are they advisable? J Fam Plann Reprod Health Care 2012; 38(1): 15-18.

4. Middleton AJ, Naish J, Singer N. General practitioners' views on the use of the levonorgestrelreleasing intrauterine system in young nulligravid women, in London. Eur J Contracep Reprod Health Care 2011; 16(4): 311-318.

DOI: 10.3399/bjgp13X671560

\section{Correction}

In the August 2013 print article: Iversen L, Fielding S Hannaford PC. Smoking in young women in Scotland and future burden of hospital admission and death: a nested cohort study. Br J Gen Pract 2013; DOI: 10.3399/bjgp13X670651 labridged text, in print: $\mathrm{Br} \mathrm{J}$ Gen Pract 2013; 63: 409-410), some of the data in Table 2 were incorrectly supplied. The correct data are online (Table 10).

DOI: 10.3399/bjgp13X671858 